\title{
Human activity reference database
}

\author{
Guimarães, C.P ${ }^{13}$; Cid, G.L ${ }^{13}$; Santos, V.S ${ }^{2}$; Zamberlan ${ }^{1}$, M.C.P; Pastura, F ${ }^{1}$.C.H; Abud ${ }^{1}$,G.M.D; \\ Lessa, C. ${ }^{1}$; Batista, D.S ${ }^{1}$; Fraga, M. M. ${ }^{1}$ \\ ${ }^{1}$ Instituto Nacional de Tecnologia (INT) / Ministério da Ciência e Tecnologia (MCT) \\ ${ }^{2}$ Pontifícia Universidade Católica do Rio de Janeiro (PUC) \\ ${ }^{3}$ Centro Universitário Plínio Leite
}

\begin{abstract}
The first sentence of the Abstract should follow the word "Abstract." on the same line. The abstract should be clear, descriptive, self-explanatory and no longer than 200 words. It should also be suitable for publication in abstracting services. Do not include references or formulae in the abstract.
\end{abstract}

Keywords: Human Activity Reference Database, Ergonomics, chemical laboratory

\section{Introduction}

The use of computerized systems for collecting, storing and processing the data has been of great help in the ergonomic work analysis. (JASTRZEBSKA-FRACZEK et al, 2006) These systems facilitate the application of data for later study and allow comparisons with ergonomic actions. These also help map the existing health problems in the implementation of activities at work, so you can better prepare the strategies for correction of work stations, training and qualification of workers. Entering data over the months provides control for the reduction of symptoms and health problems related to work in the long term. For designers one of the primary goals of computer-aided ergonomics is to develop software tools that allow ergonomics information to be accessed at the earliest stages of design. Designers of workplaces and products have three major tasks: one, integrating information about processes, tools, machines, parts, tasks, and human operators; two, satisfying design constraints which often conflict; and three, generating a design acceptable to all parties involved. However, this requires the designer to conduct separate analyses using several different tools, many of them are not easily applied and sometimes the information generated were difficult to translate into design data. As a result, several researchers have shifted their focus towards developing integrated tools that allow ergonomics information from several sources to be examined before an actual job is implemented a proactivea rather than reactivea approach. (Feyen, i Liu , Chaffi, Jimmerson, Joseph, 2000) Some system as ErgoMaster enables users with minimal computer expertise to easily utilize the system. The system's applications include ergonomic analysis, risk factor identification, training, as well as job and workstation redesign. The user can customize various reports and analysis. Others as the database system EKIDES (Ergonomics Knowledge and Intelligent Design System) assists designers of technical systems, equipment, products and workplaces to meet ergonomic requirements for all system components and their interactions during the planning, development and subsequent design and blueprint processes. EKIDES is a design tool in form of an electronic reference system and an evaluation tool for work places and products. (Jastrzebska-Fraczek, Rer. Nat and Bubb, 2003)

Another example of decision support system was used to evaluate and control physical job stresses and prevent re-injury of workers who have experienced or are concerned about work-related musculoskeletal disorders. This database is a software program that can stored detailed job information such as standardized work data, videos, and upper-extremity physical stress ratings for over 400 jobs in the plant. Additionally, the database users were able to record comments about the jobs and related control issues. (Womack and. Armstrong, 2005) 
Human Activity Reference Database system was first developed to be applied to Oil and gas Industry for ergonomic analysis information storage by ERGON Projetos e National Institute of Technology in 2004. This system allowed users to acquire information to overcome difficulties from ergonomic assessments (SCHMIDTKE and JASTRZEBSKA-FRACZEK, 2000). The data was generated, treated, organized and stored after the evaluation of work situations using the following methods: Ergonomic Work Analysis (WISNER, 1995), method for biomechanical evaluation and kinesiology, method for dimensional evaluation (anthropometry) and method for evaluating the perception of pain and discomfort .

As the methods and systematic observations of the work were applied and analyzed for the Oil and Gas Industry, the results indicated that we could divide in two categories of activities: characteristics of the computerized work in offices and characteristics of work in production (SANTOS et al, 2009).

In the activity of characteristics of the computerized work in offices were identified a presence of multiple activities, simultaneously or not; a great variability of activities according to the frequency and relevance; great information flow and frequent interruptions of activities; important use of computer systems and need for training and updating during execution of work. (SANTOS et al, 2004)

Besides, in the activity of Characteristics of Work in Production were seen multiple activities, different tools and work stations; numerous activities in different locations and can lead to modifications; varied cycles according to the dynamism of the company and asymmetrical knowledge of the workers. (ZAMBERLAN et al, 2004)

The figure 1 and 2 showed the information display at the first Human Activity Reference Database system developed in 2004 to Oil and Gas industry. This database could display information about the ergonomic analysis, biomechanical and dimensional evaluation, organizational condition, priority criteria to improvement recommendations and also pictures an video from the activities analyzed.

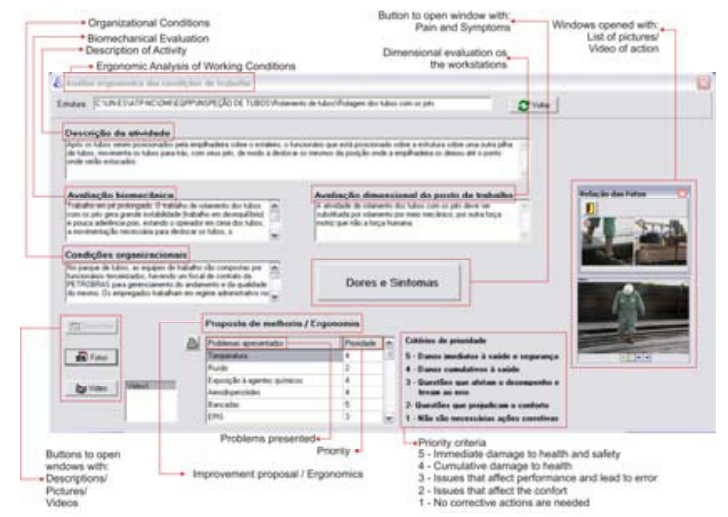

Fig 1 First Human Activity Reference Database system windows

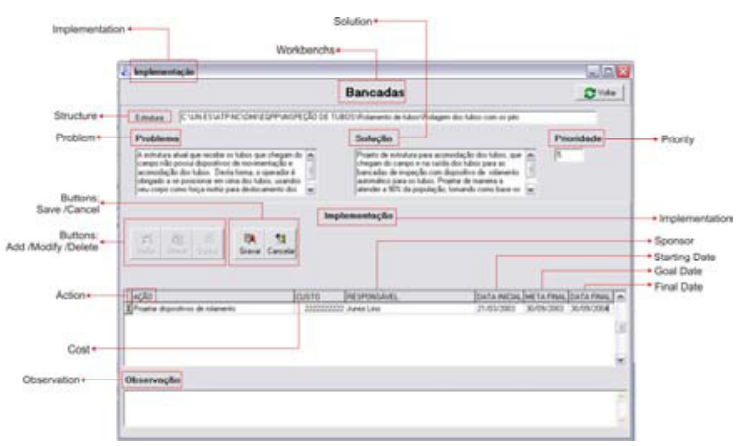

Fig. 2 - Example of information display at first Human Activity Reference Database system - Improvement recommendation windows

The goal study is to present the Human Activity Reference Database applied to ergonomic analysis of chemical laboratories in the Oil and Gas Industry.

\section{The laboratory database system}

The database has been developing in Access system and the interface in Delphi. The database comprises data generated from different methods application: the Ergonomic Work Analysis method (WISNER, 1995); kinesiology and biomechanical analysis methods (based on cinemetry, NIOSH method application, REBA method application, static strength evaluation by dynamometry, etc); dimensional analysis, 2D and 3D anthropometrics analysis and discomfort analysis method (Corlett et $\mathrm{al}$, 1980), and actual and proposed laboratory plain and simulation. It also included pictures, videos, and the ergonomic analyses, as well as floor plan. The new database system has been also developed to 
allow data entering. The data entering profile was the maim difference between this database and the old one.

The system presented the information in following windows sequence: Main windows (Fig. 3), Chemical laboratory selection and description window $\mathrm{n}$ (Fig.4) and Chemical test description windows (Fig.5).

At the main windows (Fig.3), the user can find the management and laboratory information previews insert in the system in order to allow identification of the laboratory

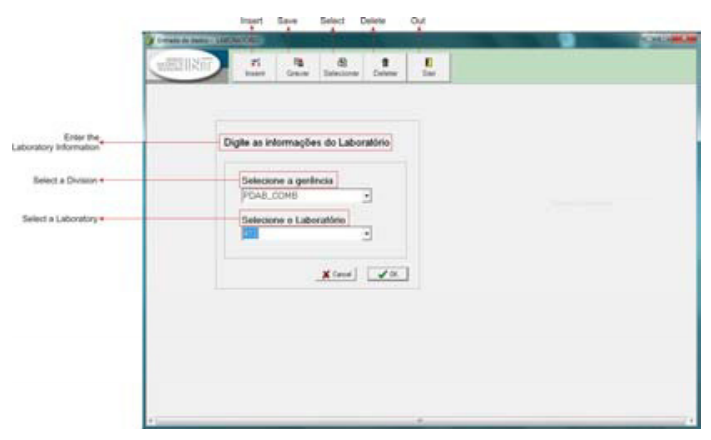

Fig 3. Main Windows

At the Chemical laboratory selection and description window (Fig.4), the user can enter and view data from ergonomic analysis, pictures and floor plain, and also the chemical tests already analyzed.

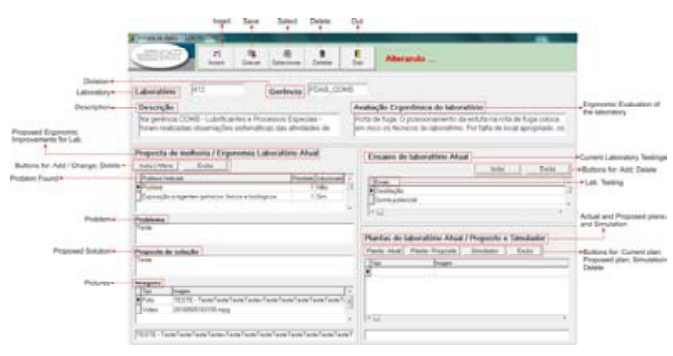

Fig4. Chemical laboratory selection and description window

At Chemical test description windows (Fig.5) the users have the descriptions of the chemical tests, as well as their pictures, videos, biomechanical analysis and equipments lists.

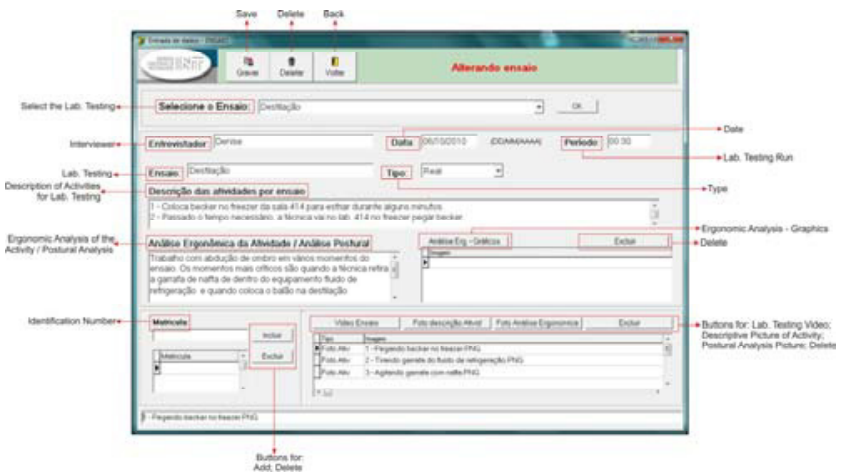

Fig 5. Chemical test description windows

\section{Conclusion}

This structure provides some improvements in collecting, organizing and storing data. Also it gives access to the real scale of problems faced by the workers and facilitates the company to have a view of the direct costs (errors, rework, occupational diseases, among others) and indirect costs (concussion company image, loss of earnings) as well as in direct costs for workers' health and safety. This also can be used as training information for new workers

\section{References}

1. Corlett, E. N., Manenica, I. The effects and measurement of working postures. Applied Ergonomics, Trondheim, v. 11, n. 1, p. 7-16, march. 1980.

2. Feyen, R., , Liu, Y.,, Chaffin, Don, Jimmerson, G., and Joseph, B., 2000, Computer-aided ergonomics: a case study of incorporating ergonomics analyses into workplace design, Applied Ergonomics 31, p. 291-300

3. Hignett, S., Mcatamney, L., 2000; Rapid Entire Body Assessment (REBA), Applied Ergonomics, vol. 31, p. $201-205$

4. Santos, V.S, Guimarães, C.P, Setti, M.E.C, Zamberlam, M.C.P, Pastura, F.C.H, Cid,G.L., 2004, Ação Ergonômica Métodos de Avaliação no Trabalho/Banco de dados Referencial das Atividades Humanas, XIII Congresso Brasileiro de Ergonomia Fortaleza

5. Santos, V., Zamberlam, M.C., Pavard, B., 2009, Confiabilidade Humana e Projeto Ergonômico de Centros de Controle de Processos de Alto Risco, IBP, cap. 10 , p. $259-267$

6. Schmidtke, H., Jastrzebska-Fraczek, I., 2000, The ergonomic database system (EDS) - an example of computer-aided production of ergonomic data for the design of technical systems. In: Landau, K.; (Hrsg.). Ergonomic Software Tool in Product and Workplace 
Design, S.214-229. Verlag ERGON GmbH. Stuttgart 2000

7. Wisner A., 1995, Understanding problem building: Ergonomic work analysis. Ergonomics, 38, 3,595-605.

8. Womack, S.K. and Armstrong, T.J , 2005, Use of a Computerized Decision Support System for Primary and Secondary Prevention of Work-Related MSD Disability, Journal of Occupational Rehabilitation, Vol. 15, No. 3 ,

9. Zamberlam, M.C.P., Guimarães, C.P., Santos, V.S., Setti, M.E.C., Pastura, F.C.H, Cid, G.L., 2004, Banco de Dados Referencial da Atividade Humana, XIII Congresso Brasileiro de Ergonomia Fortaleza.
10. Jastrzebska-Fraczek I., Schmidtke, H. Bubb, H.; Karwowski, W.: Ergonomics Knowledge and Intelligent Design System (EKIDES) - Software Tool for Design, Assessment and Ergonomic Teaching. In: Karwowski, W. (Ed.): International Encyclopedia of Ergonomics and Human Factors. Vol 2. Boca Raton: Taylor \& Francis, 2006, p. 1613-1625

11. Jastrzebska-Fraczek I., Bubb H. (2003). Software Design and Evaluation by Ergonomics Knowledge and Intelligent Design System (EKIDES).

PsychNology Journal, 1(4), 378 - 390. Retrieved [month] [day], [year], from www.psychnology.org 